\title{
ACUTE PHASE REACTANT PROTEINS, ANTHROPOMETRIC AND DYSLIPIDAEMIC CHANGES ASSOCIATED WITH TYPE 2 DIABETIC MELLITUS AMONG NIGERIAN POPULATION
}

\author{
"Ekun, O. A., Sangotokun, O. A., Eweje, O. A., Azenabor, A. and Akinloye, O. \\ Department of Medical Laboratory Science, College of Medicine of the University of Lagos. \\ *Author for Correspondence. E-mail: ayodele1619.oe@gmail.com; Tel: +2348033151619
}

(Received: $23^{\text {th }}$ June, 2018; Accepted: $22^{\text {nd }}$ September, 2018)

\section{ABSTRACT}

\begin{abstract}
Diabetes mellitus is a serious metabolic disorder of multiple aetiology. This disorder is on the increase in some developing countries such as Nigeria. It is characterized by chronic hyperglycaemia with disturbances in carbohydrate, fat and protein metabolism resulting from either defects in insulin secretion, insulin action or both. In some cases, the disease may be insidious until the patients develop complications. A total number of three hundred and seventy five individuals participated in this study out of which two hundred and twenty five were type 2 diabetic mellitus volunteers while one hundred and fifty served as control. Anthropometric measurements were taken using weighing balance, tape rule, and meter rule. C-reactive protein, fasting blood glucose, total protein, albumin and lipid profile were determined using enzyme-linked immunosorbent assay (ELISA) and Cobas chemistry auto analyzer respectively. There were a significant increase $(p<0.05)$ in weight, body mass index (BMI) waist hip ratio, fasting blood sugar, C-reactive protein, total cholesterol, triglyceride, triglyceride/high density lipoprotein (TG/HDLC), low density lipoprotein/ high density lipoprotein (LDLC/HDLC) and TC/HDLC in type 2 diabetic mellitus patients when compared with the controls. On the other hand, albumin, albumin globulin ratio and HDLC were observed to be significantly $(\mathrm{p}<0.05)$ low in diabetic volunteers when compared with controls. There was a positive association $(r=0.66, p<0.05)$ between $C$ reactive protein $(\mathrm{CRP})$ and glucose whereas a negative association $(r=-0.31, \mathrm{p}<0.05)$ was observed between CRP and albumin among diabetic mellitus group. This study suggests that diabetes mellitus is associated with increased risk of inflammation and lipid dysfunction.
\end{abstract}

Key words: Diabetes mellitus, Acute phase reactants, Lipid profile, Blood sugar.

\section{INTRODUCTION}

Diabetes mellitus (DM) is one of the noncommunicable diseases of multiple aetiology. It is a disorder that is usually characterized by chronic hyperglycaemia as well as disturbances of carbohydrate, fat and protein metabolism (WHO, 1999, WHO, 2016). It is a consequence of defects in insulin secretion, insulin action, or both (WHO, 1999; WHO, 2016). Type 2 diabetes mellitus (T2DM) on the other hand is seen in individuals who have insulin resistance. This resistance is usually as a result of relative insulin deficiency (Sato et al., 2009). The World Health Organization report (2016) indicated that about 422 million people are diabetic world-wide as at 2014. It has been reported that type 2 diabetes mellitus account for the majority (about 90\% ) of the diabetes mellitus cases (Tripathi and Srivastava, 2006; Mbanya, 2007; CDC, 2011; Shi and Hu, 2014).

Adult with diabetes mellitus have been shown to have two to four fold increased risk of cardiovascular events (Fox et al., 2004). Thus cardiovascular complications have been shown to account for about $80 \%$ of premature excess mortality in individuals with diabetes mellitus (Winer and Sowers, 2004). Moreover, it has been shown that diabetes mellitus is associated with vascular complications; this is usually caused by micro-and macro angiopathy. Thus retinal and renal micro-angiopathies cause diabetic retinopathy and nephropathy respectively. Accelerated forms of atherosclerosis accounts for macro-angiopathy in diabetes mellitus. This usually affects the coronary, carotid and peripheral arteries leading to increased risk of myocardial infarction, stroke and diabetes foot disease (Duby et al., 2004)

On the other hand, acute-phase proteins are a class of proteins whose plasma concentrations increase (positive acute-phase proteins) or decrease (negative acute-phase proteins) in response to inflammation (Cray et al., 2009). It has been shown that positive acute-phase proteins 
usually increase in concentration in diabetes mellitus (Herpers et al., 2009).

Previous studies have suggested a possible link between subclinical chronic inflammation and the pathogenesis of type 2 diabetes mellitus (Pickup et al., 1997; Pickup and Cook, 1998). Inflammation is a short-term adaptive response of the body as a component of tissue repair to deal with injuries and infections (Badawi et al., 2010). It has been suggested that in obese individual, there is an abnormal level of fatty acids that enhance chemokine release by the expanding adipose tissue (Badawi et al., 2010). This leads to activation of monocytes as well as increased secretion of proinflammatory adipokines, which in turn leads to insulin resistance in adipose tissue and other tissues, thus increasing the risk of type 2 diabetes mellitus (Larsen and Henson 1983, King, 2008). A study has also suggested that inflammatory responses possibly elicit dual roles in type 2 diabetes mellitus; it may have either a causal relationship leading to resistance to insulin or may be intensified by hyperglycaemic state resulting in type 2 diabetes mellitus complications (Nathália et al., 2013). Thus it has been estimated that about $25 \%$ of new onset of Type 2 diabetes mellitus is associated with evidence of systemic inflammation at the time of diagnosis (Zhang et al., 2009). There is a need to investigate some inflammatory markers as well as lipid among type 2 diabetic Nigerians as it is obvious that diabetes mellitus is gradually becoming a pandemic medical condition among Nigerian population. Thus this study intends to evaluate some acute phase reactant proteins and lipid among Nigerian volunteers with diabetes mellitus.

\section{MATERIALS AND METHODS \\ Study Design}

This was a cross sectional study conducted among diabetic patients that exhibited good glycaemic control at Lagos University Teaching Hospital. The patients were chosen irrespective of their mode of treatment. Informed consent was taken from the patients. A total of three hundred and seventy five (375) volunteers consisting of two hundred and twenty five (225) diabetic volunteers and one hundred and fifty (150) non-diabetic volunteers as control.

\section{Inclusion and Exclusion criteria:}

Inclusion: Adult male and female diabetic mellitus individual not less than 40 years of age (however recent 2016 WHO report on diabetes has indicated that type 2 diabetes can be seen in children) and had a good glycaemic control were all included. The cut off glucose value used for inclusion of diabetes mellitus was fasting blood glucose of $\geq 126 \mathrm{mg} / \mathrm{dl}(7.0 \mathrm{mmol} / \mathrm{l})$ (WHO, 2006) and fasting blood glucose of $\leq 100 \mathrm{mg} / \mathrm{dl}$ (5.56 mmol/l) (ADA, 2003) for non-diabetic individuals (as control).

\section{Exclusion Criteria:}

Diabetic patients with clinical evidence of diabetic complications of renal disease, retinopathy, neuropathy and liver disease were excluded from the study.

\section{Ethical Consideration}

Approval was obtained from the Research and Ethics Committee (ADM/DCST/HREC/122 and ADM/DCST/HREC/2175) of the Lagos University Teaching Hospital (LUTH) prior to the commencement of the study.

Informed consent was sought from each of the participants of the study prior to participating in any of the procedures of the study.

\section{Data Analysis}

The data collected from the study were analysed using SPSS version 21.0. Descriptive statistics of mean, standard deviation, t-test, Pearson correlation and bar chart were used to present the data. The level of significance was set at $\mathrm{p}<0.05$.

\section{Methods:}

Blood glucose, total protein, albumin total cholesterol, triglycerides, high density lipoprotein cholesterol (HDLC) and low density lipoprotein (LDL) were analyzed using Cobas C111 chemistry auto analyzer.

\section{hs-CRP}

Serum CRP (hs-CRP) estimation was carried out using Enzyme-Linked Immunosorbent Assay (ELISA) based on the method of Engvall, and Perlmann, (1971), Engvall, and Perlmann, (1972). 


\section{RESULTS AND DISCUSSION}

In this study, anthropometric measurements of body mass index, waist circumference and waisthip ratio were evaluated (Table 1). We observed a significant increase $(p<0.05)$ in waist-hip ratio of the diabetic volunteers when compared with the non-diabetic group. There was no significant difference ( $p>0.05)$ in the mean age, body mass index and waist circumference in the two groups studied. A significant increase in waist-hip ratio a measure of central obesity among diabetic volunteers is probably an indication of central obesity among diabetes mellitus group. Previous study has shown an association between increase in waist-hip ratio and diabetes mellitus (Schmidt et al., 1992), thus suggesting that central obesity may be independently associated with type 2 diabetes mellitus. Another study on waist-hip ratio among type 2 diabetes mellitus suggested that an increase in waist-hip ratio is positively associated with complications among this group of individuals (Stuhldreher et al., 1994). A recent study has also suggested that there is a genetic association between waist-to-hip ratio and type 2 diabetes mellitus as well as chronic heart disease (Emdin $e t$ al., 2017).

Table1. Anthropometric Characteristics of the Volunteers.

\begin{tabular}{lccc}
\hline & $\begin{array}{c}\text { Diabetic } \\
\text { Mean } \pm \text { S.E.M } \\
\mathbf{n = 2 2 5}\end{array}$ & $\begin{array}{c}\text { Non- Diabetic } \\
\text { Mean } \pm \text { S.E.M } \\
\mathbf{n}=\mathbf{1 5 0}\end{array}$ & p-value \\
\hline Age (years) & $55.22 \pm 8.12$ & $56.59 \pm 9.35$ & 0.13 \\
BMI $\left(\mathrm{kg} / \mathrm{m}^{2}\right)$ & $25.67 \pm 3.66$ & $25.71 \pm 3.94$ & 0.94 \\
& & & \\
Waist circumference $(\mathrm{cm})$ & $87.97 \pm 10.42$ & $87.42 \pm 10.86$ & 0.81 \\
& & & \\
Waist/hip (ratio) & $0.94 \pm 0.08$ & $0.91 \pm 0.09$ & $0.04^{*}$ \\
Systolic blood pressure $(\mathrm{mmHg})$ & $137.93 \pm 18.97$ & $134.85 \pm 18.97$ & 0.64 \\
Diastolic blood pressure $(\mathrm{mmHg})$ & $86.14 \pm 10.58$ & $85.25 \pm 9.73$ & 0.53 \\
& & & \\
\hline
\end{tabular}

*significant $\mathrm{p}$ value $(\mathrm{p}<0.05)$

Furthermore, in table 1, it was observed that there was no significant difference $(p>0.05)$ in the systolic and diastolic blood pressure of the two volunteered groups studied. This observation might have suggested that the diabetic group selected for this study did not manifest hypertension co-morbidity as at the time of this study. Previous studies have demonstrated that tight blood glucose and blood pressure control decreased the risk of any diabetes related endpoint by $12 \%$ and $24 \%$ respectively (UK Prospective Diabetes Study group 33, 1998; UK Prospective Diabetes Study group 38, 1998). It has been demonstrated also that a tight control of blood pressure among type 2 diabetes mellitus reduces the risk of death related to diabetes mellitus by $32 \%$ (UK Prospective Diabetes Study group 38, 1998).

Moreover in table 2, we observed a significant increase $(p<0.05)$ in the plasma glucose concentration of type 2 diabetes mellitus group when compared with the non-diabetes control group. This is an expected observation based on the group of volunteers studied. One of the common finding with diabetes been a metabolic disorder is that it is characterized by hyperglycaemia (WHO, 2016). 
Table 2: Comparative analysis of Glucose, C-reactive protein (CRP), Albumin, Total protein, Globulin and Albumin/Globulin ratio in Diabetics and Non-Diabetics

\begin{tabular}{llccc}
\hline Variables & $\begin{array}{c}\text { Diabetic } \\
\text { Mean } \pm \text { S.E.M } \\
\mathbf{n}=\mathbf{2 2 5}\end{array}$ & $\begin{array}{c}\text { Non-Diabetic } \\
\text { Mean } \pm \text { S.E.M } \\
\mathbf{n}=\mathbf{1 5 0}\end{array}$ & t-value & p-value \\
\hline Plasma Glucose $(\mathrm{mg} / \mathrm{dl})$ & $162.64 \pm 3.21$ & $72.73 \pm 1.29$ & 26.01 & $0.000^{*}$ \\
hs-CRP (mg/l) & $4.09 \pm 0.91$ & $1.30 \pm 0.50$ & 2.69 & $.009^{*}$ \\
Total protein (g/l) & $73.50 \pm 1.85$ & $77.64 \pm 0.71$ & 0.43 & .0664 \\
Albumin (g/l) & $43.48 \pm 0.76$ & $46.99 \pm 1.28$ & 2.36 & $0.02^{*}$ \\
Globulin (g/l) & $30.02 \pm 1.62$ & $30.65 \pm 0.78$ & -1.22 & 0.229 \\
Albumin/globulin ratio & $1.45 \pm 0.16$ & $1.53 \pm 0.06$ & 3.05 & $0.004^{*}$ \\
\hline
\end{tabular}

*Significant level: $\mathrm{p}<0.05$

There was a significant increase $(p<0.05)$ in the mean value of hs-CRP among diabetic group (Table 2). This observation agrees with the previous studies of Ford (1999), Festa et al. (2000), and Frohlich et al. (2000) where it was observed that interleukin 6 (IL-6) and C-reactive protein, the two sensitive physiological markers of subclinical systemic inflammation, are associated with hyperglycaemia, insulin resistance, and overt type 2 diabetes mellitus (DM). Thus from this study, it became evident that the diabetic group might have been undergoing some inflammatory processes which in the long run could predispose them to either microvascular or macro-vascular complications. It has been suggested that the link between diabetes and inflammation is a reciprocal process (de Rekeneire et al., 2006). This is because inflammation may contribute to diabetes onset while diabetes on the other hand may contribute to continued inflammation (de Rekeneire et al., 2006). Study has shown that hyperglycaemia mediate formation of advanced glycosylation end-products. These end-products have been suggested to contribute to inflammation by producing a chronic stimulation for secretion of cytokines (Brownlee, 1995). Apart from this, some studies have associated increase in CRP with future cardiovascular complications among type 2 DM (Lindberg et al., 1991, Ridker et al., 1997). Cardiovascular events on the other hand have been noted to be important cause of diabetes mellitus deaths accounting for $15 \%$ of all DM deaths in Nigerians (Ogbera et al., 2009).
Furthermore we observed a non-significant decrease $(\mathrm{P}>0.05)$ in the total protein value of the diabetic when compared with the control group. However serum albumin and albumin globulin ratio were significantly lower in the diabetic group $(p<0.05)$. Our finding with respect to albumin is in consonance with the previous study of Shaper et al., (2004) where a significant lower result was observed in albumin among type II DM. This might suggest that albumin is a negative acutephase reactant protein (Ritche et al., 1999), as it has been shown that negative acute-phase proteins are reduced in response to inflammation (Herpers et al., 2009).

In addition to this, the degree of association between glucose, acute phase reactant proteins and marker of inflammation were evaluated (Table 3). We observed a positive and significant $(p<0.05)$ association between glucose and CRP. This observation suggests that hyperglycaemia could provide a template for inflammatory processes as increase in CRP clearly suggests inflammatory activities. It has been suggested that inflammation plays a pivotal role in the pathogenesis of type 2 diabetes mellitus and its complications (Donath and Shoelson, 2011). Studies have shown that dysglycaemia is associated with inflammation in diabetic individuals as well as individuals with impaired fasting and impaired glucose tolerance results (Barzilay et al., 2001, de Rekeneire et al., 2006). Thus it has been shown that type 2 diabetes mellitus is associated with higher levels of CRP, 
interleukin-6 and tumour necrosis factor- $\alpha$ markers of subclinical systemic inflammation (Yudkin et al., 1999, Barzilay et al., 2001). A lowgrade systemic inflammation has been seen to play an important role in the pathogenesis of some glucose disorder in adults (Pickup and Crook,
1998). It has been suggested that visceral fat contribute the most to the attenuation of the association between diabetes and inflammation. This could possibly explain the relationship between diabetes and C-reactive protein as also observed in this study.

Table 3. Ratio of Lipid Profile between Diabetic participants and Non-Diabetic participants

\begin{tabular}{llll}
\hline & $\begin{array}{l}\text { Diabetic } \\
\text { Mean } \pm \mathbf{~ S D} \\
\mathbf{n}=\mathbf{2 2 5}\end{array}$ & $\begin{array}{l}\text { Non-diabetic } \\
\text { Mean } \pm \mathbf{~ S D} \\
\mathbf{n}=\mathbf{1 5 0}\end{array}$ & P value \\
\hline TC/HDL ratio & $6.3 \pm 2.45$ & $3.30 \pm 0.65$ & $0.05^{*}$ \\
TG/HDL ratio & $6.6 \pm 1.87$ & $3.61 \pm 0.81$ & $0.04^{*}$ \\
LDL/HDL ratio & $4.0 \pm 1.96$ & $1.75 \pm 0.44$ & $0.03^{*}$ \\
\hline
\end{tabular}

*significant $\mathrm{p}$ value $(\mathrm{p}<0.05)$

Thus adiposity in particular visceral adipose tissue, has been found to be an important promoter of low-grade chronic inflammation (Forouhi et al., 2001, Pannacciulli et al., 2001). It is important to know that a negative and significant relationship $(p<0.05)$ existed between CRP and albumin. This observation possibly confirms the fact that CRP is a positive acute phase reactant, while albumin on the other hand is a negative acute phase reactant.

Figure 1 and table 3 show comparative analysis of serum lipid and lipid ratio respectively. Significant increase $(\mathrm{p}<0.05)$ in the levels of total cholesterol, LDL-cholesterol and triglyceride, as well as a significant decrease $(p<0.05)$ in HDL-cholesterol were observed in the diabetic mellitus volunteers. Our finding with respect to lipid profile suggests that type 2 diabetes mellitus may be associated with dyslipidemia. Thus our findings are in consonance with the previous study of Nakhjavani et al., (2006) who observed that there was an alteration in the lipid profile in diabetes mellitus. Dyslipidemia according to Barretconnor et al., (1982) was observed to predispose diabetic mellitus patients to cardiovascular complications with time. It has been suggested that in type 2 diabetes mellitus, insulin resistance increases mobilization of free fatty acid from adipose tissue. There is increased hepatic production of very low density lipoprotein via lipogenesis as well as decreased apolipoproteins B degradation, resulting in low HDL-cholesterol, high triglycerides ( $T G s$ ), Increased apolipoproteins B synthesis and small dense LDL-particles (Cannon, 2008). 


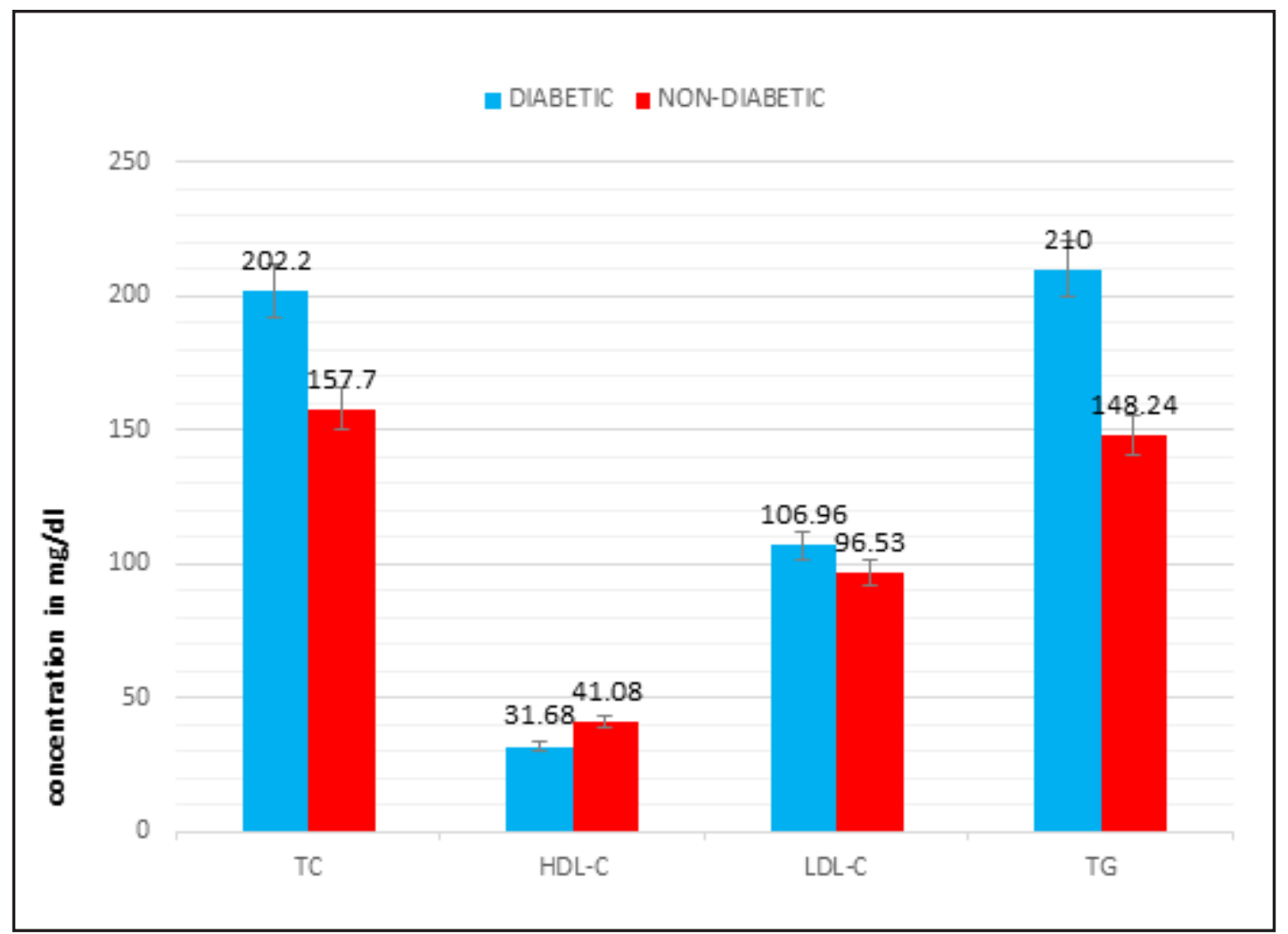

Figure 1: Showing Concentration of Lipid Analytes in Diabetic and Non-diabetic Participants

Table 4: Pearsons' Correlation between parameters in Diabetic subjects

\begin{tabular}{lcl}
\hline Association between variables & Correlation coefficient $(\mathbf{r})$ & p value \\
\hline Glucose vs CRP & 0.66 & $0.000^{*}$ \\
CRP vs Total protein & 0.04 & 0.626 \\
Total protein vs Glucose & 0.03 & 0.865 \\
Albumin vs Glucose & -0.11 & 0.455 \\
Globulin vs Albumin & -0.17 & 0.278 \\
CRP vs Albumin & -0.31 & $0.035^{*}$ \\
Total protein vs Albumin & 0.53 & $0.000^{*}$ \\
\hline
\end{tabular}

*Significant level: $\mathrm{p}<0.05 \mathrm{CRP}=$ C-reactive protein.

Thus it has been shown that the dense LDLparticle subtype is more inclined to oxidation, playing an important role in atherogenesis. Thus in type 2 diabetes mellitus, athrogenic dyslipidemia (as characterized by low HDLcholesterol and apo A, elevated fasting or 2 hour post prandial triglyceride, elevated LDLcholesterol and apo B) is a predictor of cardiovascular risk (Sorrentino et al., 2010). It is interesting to note that high density lipoprotein cholesterol (HDL-C) acts by enhancing the removal of cholesterol from the peripheral tissues and so reduces the body's cholesterol pool. However in this study we observed a significantly low HDL-C $(p<0.05)$ among the diabetic group. This observation with respect to low HDL-C observed in diabetic group might have possibly compromised the effective removal of cholesterol from the peripheral tissues of this group of individuals thus leading to increased body cholesterol pool. It has been shown that in type 2 diabetes mellitus, the protective function of HDL-cholesterol may be lost due to alteration of protein resulting in a pro-oxidant inflammatory 
phenotype (Sorrentino et al., 2010).

Previous study has shown that low HDLcholesterol concentrations are often accompanied by high triglycerides levels (Assman and Schulte, 1993). As observed in this study, there was a significantly low HDL-C and a significantly raised triglyceride among diabetic volunteers that participated in this study. This combination has been strongly associated with an increased risk of Coronary Heart Disease (Assman and Schulte 1993; Chapman et al., 2011; Miller et al., 2011). Other studies have shown that a low HDLcholesterol in the presence of a normal LDLcholesterol is an independent cardiovascular risk marker (Barter et al., 2007, Baigent et al., 2010).

A significantly $(\mathrm{p}<0.05)$ raised $\mathrm{TG} / \mathrm{HDL}$, LDL/HDL and a borderline TC/HDL ratio among the diabetic mellitus group (Table 3) were observed. These findings agree with the previous findings of Grundy (2006) where he described the dyslipidemic state as lipid triad and their associated atherogenic effect. It has been shown that lipid ratios are good predictors of cardiovascular events (Di Angelantonio et al., 2009). Previous studies have shown that the diagnosis of diabetes doubles the cardiovascular risk in men and more than triples the risk in women (Haffner et al., 1998; Mogensen, 2003). Thus the lipid ratios evaluated in this study gives a clearer and direct risk index of diabetic mellitus group to cardiovascular complications. As previous study has shown that the higher the lipid ratios the higher the risk index of cardiovascular complications among the diabetic mellitus subjects (UKPDS 1995).

Furthermore, table 4 showed the level of association between some analytes measured. There was an inverse relationship between CRP and albumin $(\mathrm{p}<0.05)$. Albumin and glucose on the other hand showed a non-significant inverse relationship $(\mathrm{p}>0.05)$. There was a positive association between CRP and glucose as well as between total protein and albumin. A positive correlation between glucose and C-reactive protein possibly suggests that hyperglycemia is associated with inflammation (Ford, 1999; de Rekeneire et al., (2006). It has been suggested that a low grade inflammation contributes to the pathogenesis of diabetes mellitus (Pickup and Cook, 1998). Also, previous report has suggested that elevated C-reactive protein and tumor necrotic factor- $\alpha$ are associated with worse cardiovascular outcomes (Kablak-Ziembicka et al., 2011). Thus it appears that hyperglycemia (as often seen in diabetes mellitus) with elevated Creactive protein (marker of inflammation) may possibly predispose diabetes mellitus individuals to cardiovascular complications. An inverse but insignificant relationship existed between albumin and glucose. It has been shown that poorly controlled diabetes mellitus is associated with lower plasma albumin concentration (RodriguezSegade et al., 2005). This might possibly explain the reason for this observation. However, it has been shown that albumin plays a cardio-protective role (Daneh et al., 1998, Djousse et al., 2002). Thus lower serum albumin concentrations were associated with increased risk of coronary heart disease, cardiovascular mortality and carotid atherosclerosis (Daneh et al., 1998, Djousse et al., 2002). Hence a positive correlation between hyperglycemia and CRP as well as lower albumin concentrations in diabetes mellitus volunteers are worthy of note.

\section{CONCLUSION}

From this study it could be concluded that diabetes mellitus is associated with dyslipidemia, increased C-reactive protein, decreased albumin and albumin/globulin ratio.

Acknowledgment: Authors are grateful to clinicians and nurses that assisted in recruiting the volunteers for this study.

Conflict of interest: None declared.

\section{REFERENCES}

Assmann, G., Schulte, H., 1993. Results and conclusions of the Prospective Cardiovascular Münster (PROCAM) study G. Assmann (Ed.), Lipid Metabolism Disorders and Coronary Heart Disease. Primary Prevention, Diagnosis, and Therapy Guidelines for General Practice. 2nd ed, MMV MedizinVerlag, München (1993), p. 19.

Badawi, A., Klip, A., Haddad, P., Cole, D.E., Bailo, B.G., El-Sohemy, A., Karmali, M., 2010. 
Type 2 diabetes mellitus and inflammation: Prospects for biomarkers of risk and nutritional intervention. Diabetes Metabolic, Syndrome Obesity. 3:17386.

Baigent C., Blackwell L., Emberson J., Holland L.E., Reith C., Bhala N., Peto R., Barnes E.H., Keech A., Simes J., Collins R., 2010. Efficacy and safety of more intensive lowering of LDL cholesterol: a metaanalysis of data from 170,000 participants in 26 randomized trials. Lancet, 376:1670-1681.

Barrett-Connor E., Grundy S.M., Holdbrook M.J., 1982. Plasma lipids and diabetes mellitus in an adult community. American. Journal. Epidemiology, 115: 657-663.

Barter P., Gotto A.M., LaRosa J.C., Maroni J., Szarek M., Grundy S.M., Kastelein J.J., Bittner V., Fruchart J.C., 2007. HDL cholesterol, very low levels of LDL cholesterol, and cardiovascular events. New England Journal Medicine, 357:1301-1310.

Barzilay J.I., Abraham L., Heckbert S.R., Cushman M., Kuller L.H., Resnick H.E., Tracey R.P., 2001. The relation of markers of inflammation to the development of glucose disorders in the elderly: the Cardiovascular Health Study. Diabetes care, 50:2384-2389.

Brownlee M., 1995. Advanced Protein glycosylation in diabetes and aging. Annual Review of Medicine, 46:223-234.

Cannon C.P., 2008. Mixed dyslipidemia, metabolic syndrome, diabetes mellitus, and cardiovascular disease: clinical implications. American Journal Cardiology, 102:5L-9L.

Chapman M.J., Ginsberg H.N., Amarenco P., Andreotti F., Borén J., Catapano A.L., Descamps O.S., Fisher E., Kovanen P.T., Kuivenhoven J.A., Lesnik P., Masana L., Nordestgaard B.G., Ray K.K., Reiner Z., Taskinen M.R., Tokgözoglu L., TybjærgHansen A., Watts G.F., European Atherosclerosis Society Consensus Panel. 2011. Triglyceride-rich lipoproteins and high-density lipoprotein cholesterol in patients at high risk of cardiovascular disease: evidence and guidance for management. European Heart Journal, 32:1345-1361.

Cray C., Zalas J., Altman N.H., 2009. Acute phase response in animals, a review. Comparative Medicine, 59(6):517-526.

Danesh J., Collins R., Appleby P., Peto R., 1998. Association of fibrinogen, C-reactive protein, albumin, or leukocyte count with coronary heart disease: meta-analyses of prospective studies. Journal of American Medical Association, 279:1477-1482.

de Rekeneire N., Peila R., Ding J, Colbert L.H., Visser M., Shorr R.I., Kritchevsky S.B., Kuller L.S., Strotmeyer E.S., Schwartz A.V., Vellas B., Harris T.B., 2006. Diabetes, Hyperglycaemia and inflammation in older individuals. The Health, Aging and Body Composition Study. Diabetes care, 29(8):1902-1908.

Department of Health and Human Services. Centres for Disease Control and Prevention, 2011. National diabetes fact sheet: national estimates and general information on diabetes and prediabetes in the United States, 2011. Available at http://www.cdc.gov/diabetes/pubs/pdf /ndfs_2011.pdf (Accessed June, 15th 2018).

Di Angelantonio E., Sarwar N., Perry P., Kaptoge S., Ray K.K., Thompson A., Wood A.M., Lewington S., Sattar N., Packard C.J., Collins R., Thompson S.G., Danesh J., 2009. Major lipids, apolipoproteins, and risk of vascular disease. The Journal of American Medical Association, 302:1993-2000.

Djousse L., Rothman K.J., Cupples L.A., Levy D., 2002. Ellison RC. Serum albumin and risk of myocardial infarction and all-cause mortality in the Framingham Offspring Study. Circulation, 106:2919-2924.

Donath M.Y., Shoelson S.E., 2011. Type 2 diabetes as an inflammatory disease. Nature Reviews Immunology, 11(2): 98-107.

Duby J.J., Campbell R.K., Setter S.M., White J.R., Rasmussen K.A., 2004. Diabetic neuropathy: an intensive review. American Journal of Health System Pharmacy, 61: 160-173.

Emdin C.A., Khera A.V., Natarajan P., Klarin D., Zekavat S.M., Hsiao A.J., Kathiresan S., 
2017. Genetic association of waist-to-hip ratio with cardiometabolic traits. Type 2 diabetes, Coronary Heart Disease. The Journal of American Medical Association, 317(6): 626-634.

Engvall, E., and Perlmann P., 1971. Enzyme linked immunosorbent assay (ELISA). Quantitative assay of immunoglobulin G. Immunochemistry, 8: 871-874.

Engvall, E., and Perlmann P., 1972. Enzyme linked immunosorbent assay (ELISA). III. Quantitation of specific antibodies by enzyme-labelled anti-immunoglobulin in antigen coated tubes. Journal Immunology, 109: 129-135.

Festa A., D'Agostino R., Howard G., Mykkänen L., Tracy R.P., Haffner S.M., 2000. Chronic subclinical inflammation as part of the insulin resistance syndrome: the Insulin Resistance Atherosclerosis Study (IRAS). Circulation, 102:42-47.

Ford E.S., 1999. Body mass index, diabetes, and Creactive protein among U.S. adults. Diabetes Care, 22:1971-1977.

Forouchi N.G., Sattar N., Mckeigue P.M., 2001. Relation of $\mathrm{C}$ - reactive protein to body fat distribution and features of metabolic syndrome in Europeans and South Asians. International Journal of Obesity and Related Metabolic Disorder, 25:1327-1331.

Fox C.S., Coady S., Sorlie P.D., Levy D., Meigs J.B., D'Agostino R.B. Sr., Wilson P.W., Savage P.J., 2004. Trends in cardiovascular complications of diabetes. The Journal of American Medical Association, 292(20): 2495-2499.

Frohlich M., Imhof A., Berg G., Hutchinson W.L., Pepys M.B., Boeing H., Muche R., Brenner H., Koenig W., 2000. Association between C-reactive protein and features of the metabolic syndrome: a populationbased study. Diabetes Care, 23:1835-1839.

Grundy S.M., 2006. Atherogenic dyslipidemia associated with metabolic syndrome and insulin resistance. Clinical Cornerstone, 8(Suppl1):S21-7.

Haffner S.M., Lehto S., Rönnemaa T., Pyörälä K., Laakso M., 1998. Mortality from coronary heart disease in subjects with type 2 diabetes and in nondiabetic subjects with and without prior myocardial infarction.
New England Journal of Medicine, 339:229-234.

Herpers B.L., Endeman H., De Jong B.A.W., de Jong B.M., grutters J.C., Biesma D.H., van velzen-Blad H., 2009. Acute-phase responsiveness of mannose-binding lectin in community-acquired pneumonia is highly dependent upon MBL2 genotype. Clinical \& Experimental immunology, 156(3):488-94.

Kablak-Ziembicka A., Przewlocki T., Sokolowski A., Tracz W., Podolec P., 2011. Carotid Intima-media thickness, hs-CRP and TNF-alpha are independently associated with cardiovascular event risk in patients with atherosclerotic occlusive disease. Atherosclerosis, 214:185-190.

King G.L., 2008. The role of inflammatory cytokines in diabetes and its complications. Journal of Periodontology, 79:1527-1534.

Larsen G.L., Henson P.M., 1983. Mediators of inflammation. Annual Review of Immunology, 1:335-359.

Lindberg G., Eklund G., Gullberg B., Rastam L., 1991. Serum sialic acid concentration and cardiovascular mortality. British Medical Journal, 302:143-146.

Mbanya, J.C., 2007. The burden of type 2 diabetes mellitus in the African diaspora. Available at www.medscape.com/view article/560718_2

Miller M., Stone N.J., Ballantyne C., Bittner V., Criqui M.H., Ginsberg H.N., Goldberg A.C., Howard W.J., Jacobson M.S., KrisEtherton P.M., Lennie T.A., Levi M., Mazzone T., Pennathur S., American Heart Association Clinical Lipidology, Thrombosis, and Prevention Committee of the Council on Nutrition, Physical Activity, and Metabolism; Council on Arteriosclerosis, Thrombosis and Vascular Biology; Council on Cardiovascular Nursing; Council on the Kidney in Cardiovascular Disease. 2011. Triglycerides and cardiovascular disease: a scientific statement from the American Heart Association. Circulation, 123:2292-2333.

Mogensen C.E., 2003. New treatment guidelines for a patient with diabetes and 
hypertension. Journal of Hypertension Supplement, 21:S25-S30.

Nakhjavani M., Esteghamati A.R., Esfahanian F., Heshmat A.R., 2006. Dyslipidemia in type 2 Diabetes mellitus: More athergnenic lipid profile in women. Acta Med. Iranica, 44(2): 111-118.

Nathália G.C., Lirlândia P.S., Marinez O.S., Nathalia T.P., Ana P.F., Karina B.G., 2013. The linkage between inflammation and Type 2 diabetes mellitus. Diabetes Research and Clinical Practice, 99(2):85-92.

Ogbera A.O., Fasanmade O.A., Chinenye S., Akinlade A., 2009. Characterization of lipid parameters in diabetes mellitus - a Nigerian report. International Archives of Medicine, 2: 19.

Pannacciulli N., Cantatore F.P., Minenna A., Bellacicco M., Giorgino R., De Pergola G., 2001. C-reactive protein is independently associated with total body fat, central fat, and insulin resistance in adult women. International Journal of Obesity and Related Metabolic Disorder, 25:1416-1420.

Pickup J.C., Crook M.A., 1998. Is type II diabetes mellitus a disease of the innate immune system? Diabetologia, 41:1241-1248.

Pickup J.C., Matttock M.B., Chusney G.D., Burt D., 1997. NIDDM as a disease of the innate immune system: association of acute phase reactants and interleukin-6 with metabolic syndrome X. Diabetologia, 40:1286-1292.

Ridker P.M., Cushman M., Stampfer M.J., Tracy R.P., Hennekens C.H., 1997. Inflammation, aspirin, and the risk of cardiovascular disease in apparently healthy men. (Published erratum. N Engl J Med 337:356, 1997) New England Journal of Medicine. 336:973-979.

Ritchie R.F., Palomaki G.F., neveux L.M., Navolotskaia O., Ledue T.B., Craig W.Y., 1999. Reference distributions for the negative acute-phase serum proteins, albumin, transferrin, and transthyretin: a practical, simple and clinically relevant approach in a large cohort" Journal Clinical Laboratory Analysis, 13(6):273-9.

Rodriguez-Segade S., Rodriguez J., Mayan D., Camina F., 2005. Plasma albumin concentration is a predictor of $\mathrm{HbA} 1 \mathrm{c}$ among type 2 diabetic patients, independently of fasting plasma glucose and fructosamine. Diabetes Care, 28:437-439.

Sato K.K., Hayashi T., Harita N., Yoneda T., Nakamura Y., Endo G., Kambe H., 2009. Combined measurement of fasting plasma glucose and $\mathrm{A} 1 \mathrm{C}$ is effective for the prediction of type 2 diabetes: the Kansi Healthcare study. Diabetes Care, 32:644-646.

Schmidt M., Duncan B.B., Canani L.H., Karohl C., Chambless L., 1992. Association of waisthip ratio with diabetes mellitus. Strength and possible modifiers. Diabetes Care, 15(7): 912-4.

Shaper A.J., Wannamethee S.G., Whincup P.H., 2004. "Serum albumin and risk of stroke, coronary heart disease, and mortality: the role of cigarette smoking" Journal of ClinicalEpidemiology, 57(2):195-202.

Shi Y., Hu F.B., 2014. The global implications of diabetes and cancer. Lancet, 383(9933):1947-8. doi: 10.1016/S01406736(14)60886-2.

Sorrentino S.A., Besler C., Rohrer L., Meyer M., Heinrich K., Bahlmann F.H., Mueller M., Horváth T., Doerries C., Heinemann M., Flemmer S., Markowski A., Manes C., Bahr M.J., Haller H., von Eckardstein A., Drexler H., Landmesser U., 2010. Endothelial-vasoprotective effects of high-density lipoprotein are impaired in patients with type 2 diabetes mellitus but are improved after extended-release niacin therapy. Circulation, 121:110-122.

Stuhldreher W.L., Becker D.J., Drash A.L., Ellis D., Kuller L.H., Wolfson S.K., Orchard T.J., 1994. The association of waist/hip ratio with diabetes complications in an adult IDDM population. Journal of Clinical Epidemiology, 47(5):447-58.

The Expert committee on the diagnosis and classification of diabetes mellitus (ADA) 2003. Follow-up Report on the Diagnosis of diabetes mellitus. Diabetes care, 23:31603167.

Tripathi BK, Srivastava A.K., 2006. Diabetes mellitus: complications and therapeutics. Medical Science Monitor, 12(7):RA130-147.

United Kingdom Prospective Diabetes Study 
Group, 1998. Intensive blood glucose control with sulphonylureas or insulin compared with conventional treatment and risk of complications in patients with type 2 diabetes: UKPDS 33. Lancet, 352: 837-853

United Kingdom Prospective Diabetes Study Group, 1998. Tight blood pressure control and risk of macrovascular and microvascular complications in type 2 diabetes. UKPDS 38. British Medical Journal, 317(7160):703-713.

United Kingdom Prospective Diabetes Study, 1995. Relative efficacy of randomly allocated diet, sulphonylurea, insulin, or metformin in patients with newly diagnosed non-insulin dependent diabetes followed for three years: UKPDS 13. British Medical Journal, 310, 83-88

Winer N., and Sowers J.R., 2004. Epidemiology of diabetes. Journal of Clinical Pharmacology, 44, 397-405

World Health Organization, 1999. Dept. of Noncommunicable Disease Surveillance. Definition, diagnosis and classification of diabetes mellitus and its complications: report of a WHO consultation. Part 1, Diagnosis and classification of diabetes mellitus. Geneva: World Health Organization. http://www.who.int /iris/handle/10665/66040.

World Health organization 2006. Definition and diagnosis of diabetes mellitus and intermediate hyperglycemia. Report of a WHO/IDF Consultation.

World Health Organization 2016. Global Reports on diabetes.

Yudkin J.S., Stehouwer C.D., Emeis J.J., Coppack S.W., 1999. C-reactive protein in healthy Subjects, associations with obesity, insulin resistance, and endothelial dysfunction; a potential role for cytokines originating from adipose tissue? Arteriosclerosis, Thrombosis, and Vascular Biology, 19: 972-978.

Zhang Y., Dall T.M., Mann S.E., Chen Y., Martin J., Moore V., Baldwin A., Reidel V.A., Quick W.W., 2009. The economic costs of undiagnosed diabetes. Population Health Management, 12:95-101. 